\title{
ACUTE POISONING AMONG CHILDREN ADMITTED TO A REGIONAL UNIVERSITY HOSPITAL IN NORTHERN GREECE
}

\author{
Aggelos Tsalkidis', George Vaos², Stefanos Gardikis², Katerina Kambouri², Gregorios Tripsianis ${ }^{3}$, Elpis Man- \\ tadakis ${ }^{1}$, Emmanuel Paraskakis ${ }^{1}$, Athanassios Chatzimicael ${ }^{1}$ \\ ${ }^{1}$ Department of Paediatrics, ${ }^{2}$ Department of Paediatric Surgery, ${ }^{3}$ Department of Medical Statistics, Alexandroupolis University Hospital, Democri- \\ tus University of Thrace School of Medicine, Alexandroupolis, Greece
}

\section{SUMMARY}

Objectives: The aim of our study was to elucidate the current pattern of acute poisoning among children admitted to a regional University Hospital in the prefecture of Evros in Northern Greece. We also compared the obtained findings with those of two previous studies performed in the same region.

Methods: Demographic and clinical data, management, and outcome of children with acute poisoning were recorded in our region, during the past 5-years (2005-2009, period C) and compared to similar studies carried out in the periods 1985-1989 (period A) and 1995-1999 (period B).

Results: Comparison between the three periods showed that in period A the lower incidence of children's acute poisoning (CAP) was observed. Also this revealed a $20 \%$-reduction in the frequency of poisoning over the past 5 -years (period $C)$ compared to period $B(p=0.219)$, a significant increase in tobacco intoxication over the years (in the order $A-C ; p<0.001$ for comparisons of periods $A$ and $B$, and periods $B$ and $C$ ), while poisoning from insecticides-pesticides decreased $(p<0.001)$. The incidence of poisoning via salicylates significantly reduced from $9.7 \%$ in period $A$ to $6.2 \%$ in period $B$, and further to $4.7 \%$ in period $C(p=0.016)$, whereas during the same periods poisoning via paracetamol increased from $2.3 \%$ to $5.1 \%$ and then to $10.4 \%$, respectively $(p<0.001)$. A trend toward a higher incidence of suicide attempt via poisoning was found during the three periods (from $3.0 \%$ in period $A$ to $4.7 \%$ and $6.6 \%$, in periods $B$ and $C$, respectively; $p=0.049$ ).

Conclusions: The frequency of acute poisoning among children has decreased over the past 5 years. The incidences of poisoning via paracetamol and tobacco, and attempted suicide have increased in recent years. Targeted and continuous educational preventive programs are mandatory.

Key words: child, emergency medicine, medication, poisoning, toxic substances

Address for correspondence: G. Vaos, Department of Paediatric Surgery, Alexandroupolis University Hospital, Democritus University of Thrace School of Medicine, 68100 Alexandroupolis, Greece. E-mail: gvaos@med.duth.gr

\section{INTRODUCTION}

Acute poisoning among children remains a major health problem $(1,2)$. Although there are educational programs and public campaigns designed to prevent children's acute poisoning (CAP), it continues to be a common medical emergency in the pediatric population (3). The pattern of incidence and the risk factors for $\mathrm{CAP}$ change with time and differ from country to country (4-6), and between geographical areas within the same country $(7,2)$. Two studies of CAP have already been undertaken at our institution $(8,9)$. The incidence of CAP was evaluated in both of these studies, in the first during the period 1985-1989 (period A) and in the second during the period 1995-1999 (period B). As the lifestyle of our society has altered over recent years, it is reasonable to suppose that the pattern of CAP has also changed. We have therefore completed a new prospective study, which covers the period 2005-2009 (period C), to assess the current pattern of CAP in the prefecture of Evros, and compared this with the two aforementioned studies (periods A and B).

\section{METHODS}

Children up to 14 years old who were admitted with acute poisoning to the Department of Pediatrics of Alexandroupolis University Hospital, a regional general and children's Hospital in the region of Thrace in Northern Greece, between January 2005 and December 2009 (period C) were enrolled in this study. The geographical target area was the prefecture of Evros, and the number of children aged up to 14 years according to the 2001 census was 20.809 . The total prevalence of parental education level in the population of our region according to the same census was $21.1 \%, 42.0 \%$ and $36.9 \%$ for elementary, secondary education, and tertiary education respectively. The Department of Pediatrics is the only primary pediatric department in the prefecture of Evros so this paper represents the pattern of CAP among children in this region.

The information about each case was recorded on standardized forms, and a chart review survey was performed. The following data were recorded for each patient: age and sex of the child, parents' education (elementary, secondary, or tertiary), type of 
residence (urban or rural), month of exposure to the poison, place where poisoning occurred, attendant to the child at the time of the event (mother, father, relative, or babysitter), smoking habits of the parents, work status of the mother, time between the event and arrival at the hospital, toxic substance responsible for poisoning, symptomatology, initial management in the emergency room (ER), duration of stay in the hospital, outcome. Parents' education was considered as tertiary or intermediate when one or both parents had tertiary or intermediate level of education and elementary when both parents had elementary level of education. Occasionally consultation with specialists such as cardiologists and neurologists was needed; pediatric surgeons were also called to examine children with abdominal pain or vomiting in order to exclude any surgical pathology.

We compared our results (period C) to those of our two previous studies (from periods A, January 1985 to December 1989 and B, January 1995 to December 1999; with regard to the following variables: frequency, age and sex of the patients, place where the poisoning occurred, type of toxic substance involved, self-poisoning (i.e., attempted suicide via poisoning), and management. The criteria used in the selection of these comparative variables were their availability and sufficiency in the two previous studies, thus rendering the results comparable. The children population in the prefecture of Evros according to the 1981, and 1991 censuses was 33.052 and 24.706 , respectively.

Statistical analysis of the data was performed using the Statistical Package for the Social Sciences (SPSS), version 11.0 (SPSS, Inc., Chicago, IL, USA). Incidence rates and their $95 \%$ confidence intervals (CI) were calculated as the number of CAP per 100.000 children. More specifically, the calculation of the mean annual incidence rates for the three studied periods A, B and C were based on the demographic data of the 1981, 1991 and 2001 National Censuses, respectively. The normality of quantitative variables was tested with Kolmogorov-Smirnov test. All quantitative variables were expressed as the median and range, while qualitative variables were expressed as frequencies and percentages. The $\chi^{2}$ test was used to evaluate any potential association between qualitative variables and Mann-Whitney U-test was used to assess differences of quantitative variables between two groups of children. Multivariate logistic regression analysis was used to determine independent predictors of longer delay (more than 120 $\mathrm{min}$ ) before presentation to the ER after exposure to the poison and attempting suicide via poisoning. Adjusted odds ratios (aOR) and $95 \%$ confidence intervals (CI) were calculated as the measure of the above derived associations. All tests were two tailed and statistical significance was considered for $\mathrm{p}$ values less than 0.05 .

\section{RESULTS}

During the period of the present study (period C), 258 children were admitted to our institution for suspected (29.1\%) or confirmed episodes (70.9\%) of acute poisoning, accounted for $3.0 \%$ $(258 / 8562)$ of all children admissions in this period. The annual incidence of CAP was 248 (95\% CI $=187$ to 328$)$ per 100,000 children aged up to 5 years had the highest age-adjusted incidence of 581 per 100,000 children. In the age groups between 5 to 9 years and 10 to 14 years, the annual incidences were 100 per 100,000 and 77 per 100,000 children, respectively.
Table 1. Patients' characteristics

\begin{tabular}{|l|c|c|}
\hline & No of patients & Percentage (\%) \\
\hline Gender & & \\
\hline Male & 127 & 49.2 \\
\hline Female & 131 & 50.8 \\
\hline Age (months; median [range]) & $24(2-168)$ & \\
\hline$\leq 5$ years & 196 & 76.0 \\
\hline 6 -10 & 34 & 13.9 \\
\hline$>10$ years & 28 & 10.1 \\
\hline Place of poisoning & & \\
\hline Home & 220 & 85.3 \\
\hline Other & 38 & 14.7 \\
\hline Residence area & & \\
\hline urban & 168 & 65.1 \\
\hline rural & 90 & 34.9 \\
\hline Parents education & & \\
\hline elementary & 133 & 51.6 \\
\hline secondary & 117 & 45.3 \\
\hline tertiary & 8 & 3.1 \\
\hline Working mother & 71 & 27.5 \\
\hline Mother's smoking & 128 & 49.6 \\
\hline Father's smoking & 222 & 86.0 \\
\hline Supervision of children & & \\
\hline Parents & & \\
\hline Grandparents & & \\
\hline Other relatives-babysitter & & \\
\hline & & \\
\hline & & \\
\hline & & \\
\hline & & \\
\hline
\end{tabular}

Patients' characteristics are shown in Table 1. Five patients $(1.9 \%)$ had experienced poisoning in the past, and seven children $(2.7 \%)$ had a sibling who had experienced an acute poisoning event. CAP tended to occur more frequently between March and June (47.2\%). Most of the children (61.6\%) presented to the ER within the first $2 \mathrm{~h}$ of poisoning. The remaining 99 patients presented to the ER within 2-20 h after the event. Higher percentage of longer delay (more than $120 \mathrm{~min}$ ) before presentation to the ER after exposure to the poison was associated with ages older than 5 years $(48.8 \%$ vs $27.9 \%, \mathrm{p}=0.001)$, living in rural areas $(52.2 \%$ vs $31.0 \%, p=0.001)$, place of poisoning other than home ( $60.5 \%$ vs $34.5 \%, \mathrm{p}=0.002)$, no working mother ( $43.3 \%$ vs $25.4 \%$, $\mathrm{p}=0.008)$, supervision by parents and other relatives or babysitter $(41.1 \%$ and $33.3 \%$ vs $15.4 \%$ by grandparents, $p=0.034)$ and first exposure to poisoning $(39.1 \%$ vs $0 \%, p=0.075)$; it was also found to decrease with increasing level of parental education (44.4\%, $32.5 \%$, and $25.0 \%$ in families with parents who were elementary, secondary, and tertiary educated, respectively; $\mathrm{p}=0.039$ for a linear trend). The total prevalence of parental education level in the population of our region vs the respective frequencies within our cohort indicates a significant difference between the observed and expected frequencies $(\mathrm{p}<0.001)$. Children were brought to the ER under their parents own initiative in $72.1 \%$ of cases; $19.8 \%$ 
were referred by their physician and $8.1 \%$ were transported by ambulance from other district hospitals. Multivariate stepwise logistic regression analysis revealed that ages older than 5 years $(\mathrm{aOR}=2.5,95 \% \mathrm{CI}=1.4-4.4, \mathrm{p}=0.002)$, living in rural areas $(\mathrm{aOR}=2.7,95 \% \mathrm{CI}=1.3-4.8, \mathrm{p}<0.001)$, place of poisoning other than home $(\mathrm{aOR}=1.6,95 \% \mathrm{CI}=1.1-2.4, \mathrm{p}=0.022)$ and elementary or secondary level of parental education $(\mathrm{aOR}=2.3,95 \% \mathrm{CI}=1.2$ $4.5, \mathrm{p}=0.014$ ) remained significant independent determinants of longer delay (more than $120 \mathrm{~min}$ ) before presentation to the ER.

Pharmaceutical drugs were the most frequent toxic substance responsible for the poisonings (40.6\%), the most common being paracetamol (10.4\%). Tobacco was responsible for poisoning in 40 children $(15.5 \%)$, and in six $(2.3 \%)$ it was an insecticide or pesticide. The distribution of toxic substances differed significantly depending on the age $(p<0.001)$ and the sex $(p=0.001)$ of the child. In particular, poisoning as a result of ingestion of drugs or insecticides-pesticides tended to increase, while poisoning from ingestion of household products tended to decrease with the age of the child; all cigarette-related poisonings occurred in younger children $(<5$ years of age), whereas all poisonings resulting from alcohol ingestion occurred in older children $(>10$ years of age) (Table 2).

Seventeen children (6.6\%), all females and with a median age of 13 years (range, 11-14 years), attempted suicide via poisoning. If patients over 10 years of age are taken into account, the ratio of self-poisoning increases further $(60.7 \%, 17 / 28)$. Self-poisoning was thus significantly more frequent among girls ( $13.0 \%$ vs $0 \%$, $\mathrm{p}<0.001$ ), older than 10 years $(60.7 \%$ vs $0 \%$, $<<0.001)$, urban areas $(10.1 \% \mathrm{vs} 0 \%, \mathrm{p}=0.002)$ and place of poisoning other than home $(34.2 \%$ vs $1.8 \%, \mathrm{p}<0.001)$; the frequency of self-poisoning tends to decrease as parental education level increases $(11.3 \%, 1.7 \%$ and $0 \%$ in families whose parents have reached elementary, secondary, and tertiary education, respectively; $\mathrm{p}=0.002$ for a linear trend). This parameter did not differ significantly between children with working mothers and those with mothers who did not work outside the home $(7.0 \%$ vs $6.4 \%, p=0.857)$. Pharmaceutical drugs were the commonest substance used for intentional poisoning $(94.1 \%$, 16 out of 17 attempts), and these were mainly painkillers (paracetamol, 10/16) or hypnotics/ tranquilizers (e.g., diazepam, alprazolam, bromazepam; 6/16). Self-poisoning attempts tended to be more frequent between the months of April and June (53.0\%). In multivariate analysis, female gender $(\mathrm{p}=0.022)$ and living in urban areas $(p=0.016)$ remained the two significant independent risk factors for attempting suicide via poisoning.

Gastrointestinal symptoms (vomiting or abdominal pain) were noted in 28 children (10.8\%), neurological (hypotonia, ataxia, or impaired consciousness) in $41(15.8 \%)$, respiratory (dyspnea or cough) in $5(1.9 \%)$, cardiovascular (hypotension or arrhythmias) in $4(1.5 \%)$, and others in $3(1.1 \%) ; 184$ patients $(71.3 \%)$ were asymptomatic. Treatment was administered at the ER in 203 patients $(78.6 \%)$. Gastric lavage and activated charcoal was used in $18.7 \%$ and $73.8 \%$ of the patients, respectively. Antidotes were administered to $15(7.3 \%)$ of patients (N-acetyl cysteine in 9 and flumazenil in 6).

Four patients were admitted to the Pediatric Intensive Care Unit (PICU) for no less than $48 \mathrm{~h}$. The median duration of hospitalization was 3 days (range, 1-8 days). All of the patients had a benign course after the exposure to poison, without any consequence resulting from the event.

\section{Comparison between Periods A, B, and C}

The annual incidences of CAP were $179(95 \% \mathrm{CI}=136$ to 230$)$ per 100.000 in period $\mathrm{A}$ and $312(95 \% \mathrm{CI}=136$ to 230$)$ per 100.000 in period $\mathrm{B}$; $\mathrm{CAP}$ incidence exhibited highly significant elevation in period $\mathrm{B}$ compared to period $\mathrm{A}(\mathrm{p}<0.001)$. The $20 \%$-reduction of the CAP incidence in period $\mathrm{C}$, compared to period $\mathrm{B}$, did not reach the statistical significance $(\mathrm{p}=0.219)$; CAP incidence in period $\mathrm{C}$ remained marginally higher compared to period $\mathrm{A}$ $(p=0.079)$. Regarding to the percentage of CAP to the total number of admissions, poisoning accounted for the $4.8 \%$ (296/6175) and $5.2 \%(386 / 7428)$ of all children admissions in periods A and B, respectively; both percentages were significantly higher compared to period C (3.0\% [258/8562], both $\mathrm{p}<0.001)$. In Period B was a large influx of immigrants with their families who settled in the area of Evros. In this regards, a significantly higher frequency of refugee children was found among the CAP in period B compared to period $\mathrm{C}(22.5 \%$ [87/386] vs $15.3 \%$ [39/258], $\mathrm{p}=0.020 ; \mathrm{OR}=1.6$, $95 \% \mathrm{CI}=1.1-2.5)$. No resettled children were found among the $\mathrm{CAP}$ in period $\mathrm{A}$.

Table 2. Toxic substance according to children's age

\begin{tabular}{|c|c|c|c|c|c|c|c|c|}
\hline \multirow[b]{3}{*}{ Toxic substance } & \multicolumn{8}{|c|}{ Age } \\
\hline & \multicolumn{2}{|c|}{$\leq 5$ years } & \multicolumn{2}{|c|}{$6-9$ years } & \multicolumn{2}{|c|}{$>10$ years } & \multicolumn{2}{|c|}{ Total } \\
\hline & $\mathrm{n}$ & $\%$ & $\mathrm{n}$ & $\%$ & $\mathrm{n}$ & $\%$ & $\mathrm{n}$ & $\%$ \\
\hline Drugs & 69 & 35.2 & 19 & 55.9 & 17 & 60.7 & 105 & 40.7 \\
\hline Domestic products & 47 & 24.0 & 2 & 5.9 & - & - & 49 & 19.0 \\
\hline Tobacco & 40 & 20.4 & - & - & - & - & 40 & 15.5 \\
\hline Petroleum products & 15 & 7.7 & 2 & 5.9 & - & - & 17 & 6.6 \\
\hline Insecticides - Pesticides & 1 & 0.5 & 1 & 2.9 & 4 & 14.3 & 6 & 2.3 \\
\hline Alcohol & - & - & - & - & 3 & 10.7 & 3 & 1.2 \\
\hline Miscellaneous chemicals & 21 & 10.7 & 9 & 26.5 & 3 & 10.7 & 33 & 12.8 \\
\hline Unknown & 3 & 1.5 & 1 & 2.9 & 1 & 3.6 & 5 & 1.9 \\
\hline Total & 196 & 100.0 & 34 & 100.0 & 28 & 100.0 & 258 & 100.0 \\
\hline
\end{tabular}


Most of the cases occurred in children aged up to 5 years in all three time periods (A: 581 per 100.000, represented the $72.9 \%$ of CAP, B: 883 per $100.000,78.7 \%$, C: 402 per 100.000 , $76.0 \%$ ). Similarly, the boys: girls ratio remained essentially unchanged (1:1 in all three periods). The home remained the most common place where the poisoning occurred (A: $82 \%$, B: $82.4 \%, \mathrm{C}: 85.2 \%)$.

The $\chi^{2}$ test for linear trends revealed that the percentage of children with tobacco intoxication increased over the three time periods (A: $6.4 \%, \mathrm{~B}: 8.2 \%, \mathrm{C}: 15.5 \%, \mathrm{p}<0.001$ ), while poisoning from insecticides-pesticides decreased (A: $12.5 \%$, B: $8.3 \%$, C: $2.3 \%, \mathrm{p}<0.001)$. Regarding drug-related poisoning, those attributable to salicylates reduced significantly from $9.7 \%$ in period A to $6.2 \%$ in period $B$ and $4.7 \%$ in period $C(p=0.016)$, whereas poisoning attributable to paracetamol increased during the same periods (A: $2.3 \%$, B: $5.1 \%, \mathrm{C}: 10.4 \%, \mathrm{p}<0.001$ ). A statistically significant increase in the incidence of self-poisoning was found across the three periods, from $3.0 \%$ in period $A$ to $4.7 \%$ and then $6.6 \%$ in periods $B$ and $C$, respectively $(p=0.049)$.

In periods $\mathrm{A}, \mathrm{B}$ and $\mathrm{C}$, gastrointestinal decontamination was performed by gastric lavage in $27.8 \%, 23.2 \%$ and $18.7 \%$ of cases, respectively, activated charcoal in $14.3 \%, 27.9 \%$, and $73.8 \%$, and Ipecac-syrup-induced vomiting in $57.3 \%, 19.1 \%$, and $0 \%$. Admission to PICU was necessary for three and two children in periods $\mathrm{A}$ and $\mathrm{B}$, respectively.

\section{DISCUSSION}

There are many studies in the literature concerning CAP, and they are all of interest because they come from different countries with different cultures, manners, socioeconomic status, and information programs for accident prevention $(5,10)$. We believe that our study is of particular value because it provides an estimate of the current pattern of CAP in one district of Greece. It also provides longitudinal data, thus enabling comparison of results with these of two previous studies that include children from the same geographical area who were managed at the same health-care institution.

In the period $\mathrm{A}$ the incidence of CAP was significantly lower compared to periods $\mathrm{B}$ and $\mathrm{C}$. The increased incidence of CAP in the period B was probably due to the influx of refugee families who settled in the area of Evros. The family size of these families was large with 4, 5 or 6 children and experienced communication problems as result of the inadequate knowledge of language. Therefore, these situations may have played an important role as the 23 per cent of CAP in this period related to refugee children. In contrary and with accordance with other studies $(11,12)$, there has been a reduction in the incidence of CAP in recent years (period C) in comparison to the period B. This is probably due to the concomitant increase in the number of multiple and continuous public campaigns focused on child safety and awareness of prevention of accidents among children $(10,11)$, with a particular focus to the refugee families ( 15 per cent of CAP in period $\mathrm{C}$ related to refugee children).

In the three periods studied, most of the CAP events occurred among children aged up to 5 years, with a slight male or female predominance in periods A, B and C, respectively. Similar results have been reported elsewhere $(5,7,8,10)$.
The seasonal distribution of CAP in period $\mathrm{C}$, with a peak in the spring and summer, is also similar to previous findings (11, $15)$, as is the result that self-poisoning occurred more commonly during the school term-time period (16). Our results show that the level of education of the parents is a preventive factor for CAP. However, in a study from southern Greece the authors have reported that the parents' socioeconomic status is not an important risk factor (17). Furthermore, it has been reported that children who are attended by persons other than their parents are at increased risk of poisoning (17). That finding is in contrast to our finding that most of the poisoning events occurred under parental supervision. Although in this study the poisoning recurrence rate within a family was found to be lower than previously reported (1.9-2.7\% vs 3.7\%), it remains essential to seek out the high-risk families (14).

In our series, most of the CAP events were due to accidental exposure to toxic factors, mainly via oral intake in the home. The ingestion substances were mainly drugs and domestic chemical products, which are often found in the home in places that are easily accessible to children $(18,19)$. These results are consistent with those of other studies $(5,10-12)$. Nevertheless, the type of drug ingested has changed over time; in period $\mathrm{C}$, poisoning from paracetamol ingestion was more common, whereas in periods $\mathrm{A}$ and $\mathrm{B}$, the poisoning drug was more commonly salicylate. A possible explanation for this is that in recent years paracetamol has become the antipyretic/painkiller of choice (almost exclusively) for people of all ages, and can be found in every house (20-22). The incidence of poisoning from insecticides-pesticides is significantly lower in period C compared to periods A and B. This could be attributable to either an increase in the safety of the packaging of these products or because the number of children living in rural areas has decreased significantly in recent years as a consequence of migration to urban regions. The incidence of poisoning from nicotine (as a result of accidental ingestion of cigarettes and butts) increased during period $\mathrm{C}$ compared to periods $\mathrm{A}$ and $\mathrm{B}$. These results are in accordance with those from another study from Greece (17). In this study poisoning from tobacco was the second most common type of poisoning, accounting for $15 \%$ of all cases. This is probably due to the incidence of smoking among both parents - and mothers in particular - having increased over recent years (17). Although, we did not have available data about the percentage of smokers among the population of Thrace (men, women), the percentage of smokers in Greece according to $\mathrm{WHO}$, is one of the highest in Europe and ranges from $47-54 \%$. In countries in which there have been systemic antismoking campaigns, the incidence of poisoning from tobacco has decreased (10). Even though in most cases CAP events are accidental, the incidence of self-poisoning has increased markedly in recent years, with the highest incidence occurring among those over 10 years of age, predominantly female, as in our study $(11,16)$. For this reason, the attention to poisoning prevention in this age group, and in particular those who are socially deprived should be increased $(23,24)$.

In most of the cases the CAP event occurred in the home. This highlights the need to encourage the establishment of a safe domestic environment, for example by storing toxic agents in a place that is inaccessible to children. However, the lack of legislation in Greece regarding the use of safety caps and containers for hazardous substances (toxic or corrosive) and pharmaceutical 
drugs contributes to the exposure of our children to poisons, and hence to the incidence of CAP (1).

The low appearance of symptomatology and the good clinical condition of the children at admission to hospital in most of our cases could be explained by either the small quantity of toxic substance ingested or its low level of toxicity $(18,25,26)$.

All children who ingested a toxic substance, even those who were asymptomatic, were admitted to the Department of Pediatrics to enable close monitoring and initiate treatment if and when required. The use of gastric lavage was a more frequently used procedure in periods $\mathrm{A}$ and $\mathrm{B}$ than in period $\mathrm{C}$. This procedure should be undertaken within 1-2 h of ingestion of a potentially life-threatening amount of a poison (27). Ipecac syrup, which induces vomiting, was used only in periods A and $\mathrm{B}$, and not in period $\mathrm{C}$. It has been our clinical practice in recent years to avoid the use of Ipecac, in accordance with the suggestion that it confers no benefit and should be abandoned as a treatment regimen (12). Activated charcoal was the most commonly used treatment in period C $(12,27)$.

The outcome of all children was good, and the median time of hospitalization was 3 days, which is in agreement with other studies (7). Follow-up by a pediatric psychiatrist was considered necessary for all children aged more than 5 years because at these ages an increased feeling of self-protection should be engendered. Those children who had attempted self-poisoning were subjected to a systematic psychological follow-up along with their families, with the aim of avoiding a subsequent attempt.

In summary, comparison between three time periods showed that in period A (1985-1989) the lower incidence of CAP was found. Also this revealed a reduction in the frequency of CAP over the past 5 years (period C, 2005-2009) than in period B (1995-1999). Particular attention should be paid to the increased rate of intoxication from paracetamol or tobacco, and to cases of self-poisoning, which involve mainly girls aged $11-14$ years. A safe home environment should be established for children, keeping toxic substances out of their reach and targeting parents and their families with continuous educational preventive programs regarding the avoidance of exposure to poisons in childhood.

\section{REFERENCES}

1. Franklin RL, Rodgers GB. Unintentional child poisonings treated in United States hospital emergency departments: national estimates of incident cases, population-based poisoning rates, and product involvement. Pediatrics. 2008 Dec;122(6):1244-51.

2. Exiara T, Mavrakanas TA, Papazoglou L, Papazoglou D, Christakidis D, Maltezos E. A prospective study of acute poisonings in a sample of Greek patients. Cent Eur J Public Health. 2009 Sep;17(3):158-60.

3. Leveque B. Ten years of prevention of domestic accidents in France: critical analysis and proposals for the future. In: Symposium Colloque CNAM; 2005 Apr 4; Paris. Paris: CNAM; 2005. (In French.)

4. Lawson GR, Craft AW, Jackson RH. Changing pattern of poisoning in children in Newcastle, 1974-81. Br Med J (Clin Res Ed). 1983 Jul 2;287(6384):15-7.

5. Mintegi S, Fernández A, Alustiza J, Canduela V, Mongil I, Caubet I, et al. Emergency visits for childhood poisoning: a 2-year prospective multicenter survey in Spain. Pediatr Emerg Care. 2006 May;22(5):334-8.
6. Kivistö JE, Mattila VM, Arvola T, Paavola M, Parkkari J. Secular trends in poisonings leading to hospital admission among Finnish children and adolescents between 1971 and 2005. J Pediatr. 2008 Dec;153(6):820-4.

7. Uziel Y, Adler A, Aharonowitz G, Franco S, Fainmesser P, Wolach B. Unintentional childhood poisoning in the Sharon area in Israel: a prospective 5-year study. Pediatr Emerg Care. 2005 Apr;21(4):248-51.

8. Tabakis T, Kapsopoulou E, Varnalis P, Tsalkidis A, Samaras K, Karpouzas I. A study of pediatric poisoning in the region of Evros. Paediatriki. 1987 Jan;50(1):11-6. (In Greek.)

9. Tsalkidis A, Arvanitidou V, Ramatani A, Kassimos D, Androulakis I. Comparison of pediatric poisoning in the region of Evros: an analysis between two periods. In: The 41st Pan-Hellenic Pediatric Congress; 2003 Jun 13-15; Rhodos, Greece. Athens: Hellenic Paediatric Society; 2003.

10. Rajka T, Heyerdahl F, Hovda KE, Stiksrud B, Jacobsen D. Acute child poisoning in Oslo: a 2-year prospective study. Acta Pediatr. 2007 Sep;96(9):1355-9.

11. Gauvin F, Bailey B, Bratton SL. Hospitalizations for pediatric intoxication in Washington State. 1987-1997. Arch Pediatr Adolesc Med. 2001 Oct;155(10):1105-10.

12. Lamireau T, Llanas B, Kennedy A, Fayon M, Penouil F, Favarell-Garrigues JC, et al. Epidemiology of poisoning in children: a 7-year survey in a pediatric emergency care unit. Eur J Emerg Med. 2002 Mar;9(1):9-14.

13. Schieber RA, Gilchrist J, Sleet DA. Legislative and regulatory strategies to reduce childhood unintentional injuries. Future Child. 2000;10(1):11136.

14. Woolf AD, Saperstein A, Forjuoh S. Poisoning prevention knowledge and practices of parents after a childhood poisoning incident. Pediatrics. 1992 Dec;90(6):867-70.

15. Lamminpää A, Riihimäki V, Vilska J. Hospitalizations due to poisonings in Finland. J Clin Epidemiol. 1993 Jan;46(1):47-55.

16. Flanagan RJ, Rooney C, Griffiths C. Fatal poisoning in childhood, England \& Wales 1968-2000. Forensic Sci Int. 2005 Mar 10;148(2-3):121-9.

17. Petridou E, Kouri N, Polychronopoulou A, Siafas K, Stoikidou M, Trichopoulos D. Risk factors for childhood poisoning: a case-control study in Greece. Inj Prev. 1996 Sep;2(3):208-11.

18. Litovitz T, Manoguerra A. Comparison of pediatric poisoning hazards: an analysis of 3.8 million exposure incidents. A report from the American Association of Poison Control Centers. Pediatrics. 1992 Jun;89(6 Pt 1):999-1006.

19. McGuigan MA. Common culprits in childhood poisoning: epidemiology, treatment and parental advice for prevention. Paediatr Drugs. 1999 Oct-Dec;1(4):313-24.

20. Chien C, Marriott JL, Ashby K, Ozanne-Smith J. Unintentional ingestion of over the counter medications in children less than 5 years old. $J$ Paediatr Child Health. 2003 May-Jun;39(4):264-9.

21. Lam LT. Childhood and adolescence poisoning in NSW, Australia: an analysis of age, sex, geographic, and poison types. Inj Prev. 2003 Dec;9(4):338-42.

22. Riordan M, Rylance G, Berry K. Poisoning in children 1: general management. Arch Dis Child. 2002 Nov;87(5):392-6. Erratum in: Arch Dis Child. 2003 Oct;88(10):946.

23. Pelkonen M, Marttunen M. Child and adolescent suicide: epidemiology, risk factors, and approaches to prevention. Paediatr Drugs. 2003;5(4):24365.

24. Asarnow JR, Baraff LJ, Berk M, Grob C, Devich-Navarro M, Suddath R, et al. Pediatric emergency department suicidal patients: two-site evaluation of suicide ideators, single attempters, and repeat attempters. J Am Acad Child Adolesc Psychiatry. 2008 Aug;47(8):958-66.

25. Riordan M, Rylance G, Berry K. Poisoning in children 4: household products, plants, and mushrooms. Arch Dis Child. 2002 Nov;87(5):403-6.

26. Cardona J, Boussemart T, Berthier M, Oriot D. Accidental bleach ingestion in children: results of a survey in 11 anti-poison centres. Proposals for management. Pediatrie. 1993;48(10):705-9. (In French.)

27. Chyka PA, Seger D, Krenzelok EP, Vale JA; American Academy of Clinical Toxicology; European Association of Poisons Centres and Clinical Toxicologists. Position paper: Single-dose activated charcoal. Clin Toxicol (Phila). 2005;43(2):61-87. 